\title{
Diathermo-trabeculotomy ab externo: indications and long-term results
}

\author{
E. MASElli, G. GALANTino, F. PRUNERI, AND M. Sirellini \\ From the Department of Ophthalmology, Ospedale Civile di Sondrio, Italy
}

SUMMARY 'The authors present the results of 2 years' observation of 47 eyes operated with diathermo-trabeculotomy ab externo. This technique, based on a diathermic effect in association with trabeculotomy ab externo, allows an ample opening of Schlemm's canal and of the trabecular meshwork, with normalisation of intraocular pressure and outflow facility, for a period of up to 2 years, in open-angle and congenital glaucoma.

The theoretical basis of diathermo-trabeculotomy ab externo is the concept that the diathermic effect prevents or delays the normal processes of scar formation in the tissues. By applying this concept in the field of ocular microsurgery we have associated this effect of diathermy with the traditional operation of trabeculotomy so as to avoid closure of the surgical opening, which often reduces the effectiveness of the operation after an interval of time.

The problem has been solved by a trabeculotome suitably insulated except for the part which comes into contact with the canal wall on the trabecular meshwork side.

\section{Methods and material}

The technical data and the operating technique have been published in this journal (Maselli et al., 1975).

With this technique we have operated on 47 eyes, 35 of which were affected with chronic simple glaucoma, 10 with congenital glaucoma, and 2 with closed-angle glaucoma.

\section{Results}

In all cases of chronic simple glaucoma we have obtained, with a single operation, normalisation of the intraocular pressure (IOP) and an improvement in the outflow facility.

Among the 10 cases of congenital glaucoma, 8 have subsequently shown normalisation of IOP and outflow facility. In 2 cases the success has been partial, with a reduction of IOP to between 23 and $26 \mathrm{mmHg}$, and an increase of the outflow facility, which although not completely normalised, was

Address for reprints: Professor E. Maselli, Divisione Oculistica, Ospedale Civile, 23100 Sondrio, Italy decidedly above the initial values and never below 0.10.

With this technique we have also operated on 2 cases of closed-angle glaucoma, both of which showed elevated IOP within 6 months of the operation (Table 1).

The results of periodic postoperative examinations after 6,15 and 24 months are given in Tables 2, 3, and 4, showing the IOP, outflow facility, visual field, and visual acuity.

Table 1 Postoperative intraocular pressure (47 eyes)

\begin{tabular}{llll}
\hline Type of glaucoma & Cases & $1 O P \leqslant 22 \mathrm{mmHg}$ & $1 O P>22 \mathrm{mmHg}$ \\
\hline Open-angle & 35 & 33 & 2 \\
Congenital & 10 & 8 & 2 \\
Closed-angle & 2 & 1 & 1 \\
\hline
\end{tabular}

Table 2 Intraocular pressure after 6 months (43 eyes)

\begin{tabular}{llll}
\hline Type of glaucoma & Cases & $I O P \leqslant 22 \mathrm{mmHg}$ & $I O P>22 \mathrm{mmHg}$ \\
\hline Open-angle & 33 & 32 & 1 \\
Congenital & 10 & 8 & 2 \\
\hline
\end{tabular}

Table 3 Intraocular pressure after 15 months (32 eyes)

\begin{tabular}{llll}
\hline Type of glaucoma & Cases & IOP $\leqslant 22 \mathrm{mmHg}$ & $I O P>22 \mathrm{mmHg}$ \\
\hline Open-angle & 22 & 22 & 0 \\
Congenital & 10 & 8 & 2 \\
\hline
\end{tabular}

Table 4 Intraocular pressure after 24 months (18 eyes)

\begin{tabular}{llll}
\hline Type of glaucoma & Cases & $1 O P \leqslant 22 \mathrm{mmHg}$ & $1 O P>22 \mathrm{mmHg}$ \\
\hline Open-angle & 12 & 12 & 0 \\
Congenital & 6 & 6 & 0 \\
\hline
\end{tabular}


Table 5 Results more than 6 months after diathermo-trabeculotomy

\begin{tabular}{|c|c|c|c|c|c|c|c|c|}
\hline \multirow{2}{*}{$\begin{array}{l}\text { Type of } \\
\text { glaucoma }\end{array}$} & \multirow{2}{*}{ Cases } & \multicolumn{4}{|c|}{$I O P(\mathrm{mmHg})$} & \multirow{2}{*}{$\begin{array}{l}\text { Failures } \\
\text { (uncontrolled IOP) }\end{array}$} & \multirow{2}{*}{$\begin{array}{l}\text { Partial successes } \\
\text { (IOP 23-26 } \mathrm{mm} \mathrm{Hg})\end{array}$} & \multirow{2}{*}{$\begin{array}{l}\text { Successes } \\
(I O P \leqslant 22 \mathrm{mmHg})\end{array}$} \\
\hline & & $11-14$ & $15-18$ & $19-22$ & $23-26$ & & & \\
\hline Open-angle & 33 & 2 & 24 & 6 & 1 & - & $1(3 \cdot 3 \%)$ & $32(96 \cdot 7 \%)$ \\
\hline Congenital & 10 & - & 2 & 6 & 2 & - & $2(20 \%)$ & $8(80 \%)$ \\
\hline Closed-angle & 2 & - & - & - & 2 & $2(100 \%)$ & 0 & 0 \\
\hline
\end{tabular}

\section{Discussion}

From examination of these results the following conclusions may be drawn. The percentages of success after a period of 6 months differ according to the various types of glaucoma (Table 5). Diathermo-trabeculotomy undoubtedly achieves its best results in cases of chronic simple glaucoma. As regards congenital glaucoma, the percentage of successes is not inferior to that which many surgeons have obtained with trabeculotomy ab externo and with goniotomy (D'Ermo and Bonomi, 1973), and there were no complete failures.

Failure in the 2 cases of closed-angle glaucoma confirms the theroretical considerations which exclude trabeculotomy as an operation for such cases.

In conclusion, diathermo-trabeculotomy has proved harmless and without side effects, owing to the complete insulation of the probe. Sometimes at the moment of passing the current we have observed a slight retraction of the iris at its root owing to the diathermic effect; however, the pupil always becomes round and central again within 48 hours of the operation. In no case, even after a long period of time, have we noted the appearance of opacity of the lens.

The gonioscopic examination in the postoperative period has clearly shown, even in the cases controlled 2 years after the operation, an ample surgical opening of the angle, the edges of which show the signs of diathermy (Figs. 1 and 2).

The localisation of Schlemm's canal sometimes creates difficulty for the surgeon, but our experience leads us to think that, even when it is not absolutely certain that the probe is in the canal, the mere opening of the trabecular meshwork is sufficient to normalise the IOP.

Finally this method, in our opinion, overcomes the well-known limitations of trabeculotomy $a b$ externo, eliminating the principal drawback of this technique, that is to say, the high incidence of closure of the surgical opening after a short time, especially in congenital glaucoma, where scar tissue formation is frequent.

Consequently, we consider diathermo-
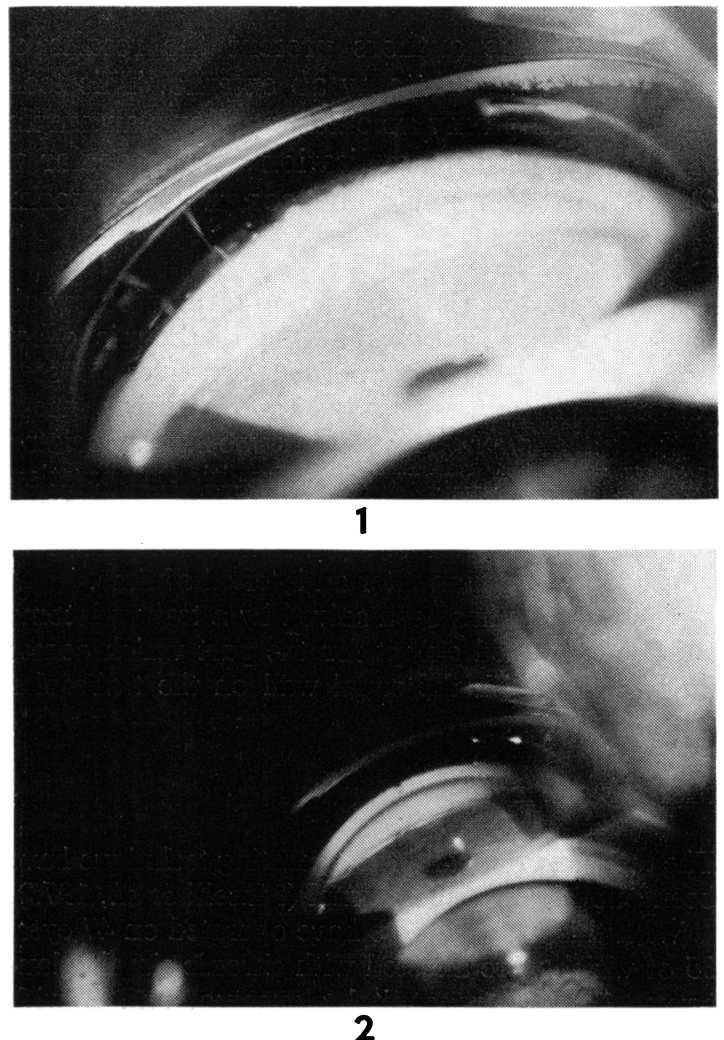

Figs. 1 and 2 Gonioscopic appearance 2 years after operation

trabeculotomy ab externo a valid alternative to simple trabeculotomy and to the trabeculectomy of Cairns in open-angle glaucoma, and to goniotomy in congenital glaucoma, particularly in those cases where corneal oedema does not permit a good view of the angle.

\section{References}

D'Ermo, F., and Bonomi, L. (1973). La Microchirurgia dell'Angolo Camerulare. Piccin: Padua.

Maselli, E., Sirellini, M., Pruneri, F., and Galantino, G. (1975). British Journal of Ophthalmology, 59, 516. 